\title{
HEAT AND EROSION-RESISTANT NANOSTRUCTURED COATINGS FOR GAS TURBINE ENGINES
}

\author{
Aleksandrs Urbahs, Konstantins Savkovs, Margarita Urbaha, Kristine Carjova \\ Institute of Aeronautics, Riga Technical University, Kalku Street 1, LV-1658 Riga, Latvia \\ E-mail:aerti@rtu.lv (corresponding author)
}

Received 14 October 2013; accepted 20 November 2013

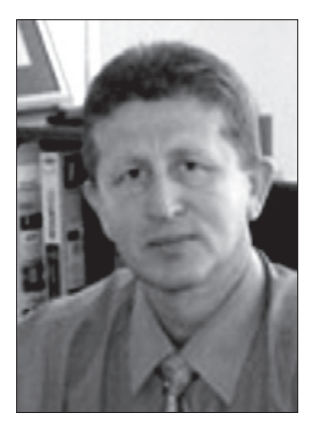

Aleksandrs Urbahs, Professor, Dr. Habil. Sc.Eng.

Date of birth: 1958

Education: 1981 - Diploma of Mechanical Engineer, Riga Civil Aviation Engineering Institute, Faculty of Mechanical Engineering. 1986 - Dr. sc.ing., Riga Civil Aviation Engineering Institute, Faculty of Mechanical Engineering. 1997 - Dr. hab. sc.ing., Riga Aviation University. Affiliations and functions: 1989-1999 - Vice Dean and Dean, Faculty of Mechanical Engineering, Riga Aviation University. Since 1999 - Full time Professor, Riga Technical University. 1999-2012 Director of the Institute of Transport Vehicles Technologies of Riga Technical University. Since 2012 Director of the Institute of Aeronautics of Riga Technical University.

Research interest: Aeronautics, Transport and Mechanical Engineering, Unmanned Vehicles, Nano-Materials, Non destructive methods of control.

Publications: 315 scientific papers and 19 patents.

Present position: Professor, Director of the Institute of Aeronautics of Riga Technical University, Expert at Latvian Council of Science ect.

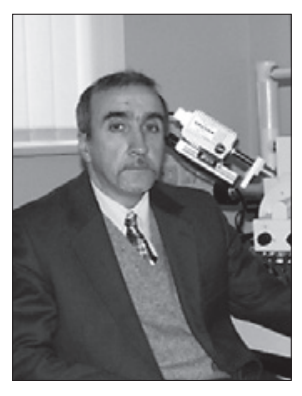

Konstantins Savkovs, Eng.

Date of birth: 1959.

Education: 1983 undergraduate of the Faculty of Mechanical Engineering Riga Civil Aviation Engineering Institute.

Affiliations and functions: 1986-1992 - Riga Civil Aviation Engineers Institute, the research sector, the latest scientific officer. 1992-1996 - Riga Aviation University, research sector, scientific officer. 1996-1999 - Riga Aviation University, Vehicle Repair and Manufacturing Technologies department engineer. 1999-2004 - served as the lead engineer at Riga Technical University, Institute of Transport Vehicles Technology. 2004-2005 - RTU Construction Materials Processing and Testing Laboratory, lead engineer. 2005-2012 - worked as a researcher and an engineer at Riga Technical University, Institute of Transport Vehicles Technology (01,004 Promotion of Science Development Fund).

Research interest: aeronautics, transport and mechanical engineering, raster electronic microscopy, material science, ion-plasma spraying.

Publications: 74 scientific papers, 6 patents and inventor's certificates.

Present position: since 2012, he has been a researcher and an engineer at the Institute of Aeronautics of Riga Technical University. 


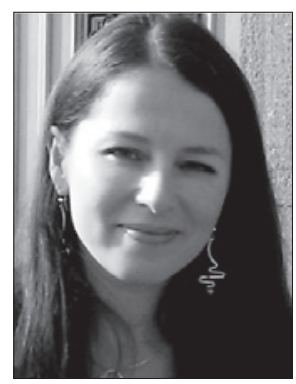

Margarita URBAHA, Dr Sc. Eng.

Date of birth: 1979.

Education: 2011 - Dr Sc. Eng., Riga Technical University, Faculty of Transport and Mechanical Engineering.

Affiliations and functions: 2006-2008 - Assistant, Riga Technical University, Faculty of Transport and Mechanical Engineering. 2008-2012 - Lecturer, Riga Technical University, Faculty of Transport and Mechanical Engineering. 2010-2012 - Researcher, Riga Technical University, Faculty of Transport and Mechanical Engineering. Since 2005 - Project Manager, Technical University, Faculty of Transport and Mechanical Engineering. Since 2012 - Senior Researcher, Technical University, Institute of Aeronautics. Since 2012 - Associate Professor, Technical University, Faculty of Transport and Mechanical Engineering.

Research interest: aeronautics, unmanned vehicles, nano-composite coatings, non-destructive methods of control, transport systems and logistics.

Publications: author of 47 articles, 39 conference presentations.

Present position: Senior Researcher, Riga Technical University, Institute of Aeronautics.

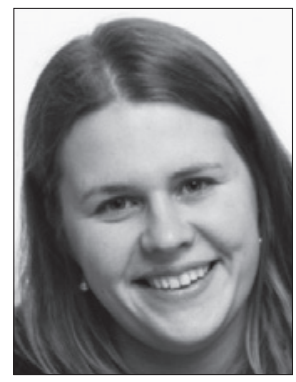

Kristine Carjova, MSc, Eng.

Date of birth: 1983.

Education: 2001-2006 - Latvian Maritime Academy Engineer ship’s navigator. 2007-2010 MSc Eng. as Master of Maritime Transport at Latvian Maritime Academy.

Affiliations and functions: 2004-2007 experience as navigator of merchant vessel. 2009-2011 captain on ASD tugboat at AS PKL Flote.

Research interests: aeronautics, nano-materials, non-destructive methods of control, structural materials, unmanned vehicles, transport systems and logistics.

Publications: author of 10 articles, 8 conference presentations.

Present position: PhD student and research assistant at Institute of Aeronautics of Riga Technical University.

Abstract. This work analyses the characteristics of functional coatings obtained by vacuum ion-plasma sputtering. These coatings have three-layer multiphase structure created as a result of condensing aluminium and titanium according to a certain programme. The article presents the results of investigation into the heat-resistance of ion-plasma coatings based on Ti-Al-N for titanium alloy parts of gas turbine engines. Analysis of the oxidation process between a sample surface and coatings within the range of $500-825^{\circ} \mathrm{C}$ was carried out. The basic features of the process of coating destruction under high-temperature oxidation conditions were determined by means of scanning electron microscopy. The results of the tests made it possible to state that the coatings developed are able to operate at temperatures of $600-750{ }^{\circ} \mathrm{C}$.

Keywords: gas turbine engines, errosian resistance, heat, coatings, sputtering technology.

\section{Introduction}

The increase in the operating efficiency of gas turbine engines (GTE) is related to the growth of their gas-dynamic cycle parameters and primarily to the growth of temperature before the turbine and the compressor compression ratio. At present the compression ratios of the compressors of powerful gas turbine engines reach 35-40 and are continuing to grow (Gunston 2007). At the same time, working temperatures of air in the last compressor stages are $500{ }^{\circ} \mathrm{C}$ and more. The required reliability of compressor blades in this case can be reached by using rather expensive nickel-chromium and other heat-resistant alloys typical for gas turbines (Lahtin, Leontieva 1990). Another alternative is the use of titanium alloys usual for a compressor or alloyed steel with thermal barrier coatings (Dorfman et al. 2004; Anikin et al. 2009).
The main causes of compressor blade destruction under the specified temperatures are gas corrosion and erosion that appears as a result of interaction between a dusty air stream and the blade surface. New technological solutions are required for the development of coatings that can assure the safe operation of aircraft.

\section{Application and main challenges}

\section{Structure and functional properties of the coating}

The research results obtained allowed creating a physical model of heat-resistant metal-ceramic nanocoatings for hot section parts of a GTE. To form the heat-resistant nanostructured coating, it was decided to use a different layer system. The peculiarity of this system is in the use of a three-layer composition, each layer of which has a different phase composition and specific microstructure and performs certain functions in the coating (Fig. 1). 


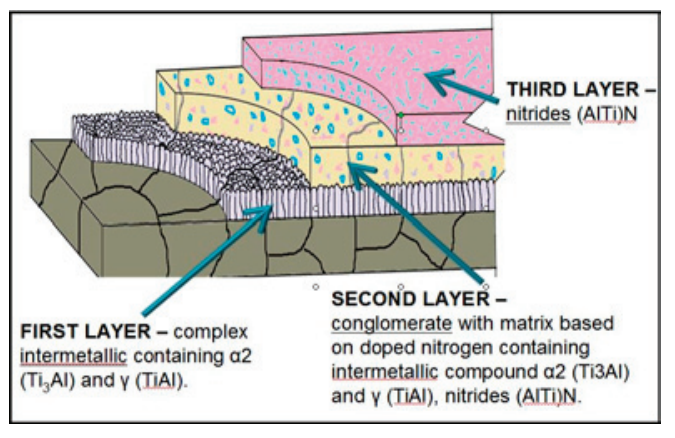

Fig. 1. The structure of the heat-resistant nanocoating

The first inner intermetallic layer based on titanium aluminide is used to create a diffusion bond between the coating and base material. It is a complex intermetallic compound containing a2(Ti3Al) and $\gamma(\mathrm{TiAl})$. This layer may contain up to $60 \%$ aluminium with the basic structure of intermetallic maintained. Unfortunately, heat-resistance above $700^{\circ} \mathrm{C}$ of intermetallic compounds is limited, and the use of this type of coating without additional protection is not very effective.

Second, the middle layer is the core and determines the thickness and heat-resistant properties of the coating. It must be a conglomerate and contain both a metallic bond in the form of titanium aluminide and complex nitrides based on titanium and aluminium of type (AlTi) N. The matrix is formed on the nitrogen-doped base complex intermetallic containing the $\alpha 2(\mathrm{Ti} 3 \mathrm{Al})$ and $\gamma(\mathrm{TiAl})$ (Fig. 2), where titanium nitride and aluminium are interspersed. Nitrides in a plastic matrix form a stable resorbable ceramic structure due to the sufficiently high resistance of the nitrides in contact with the aluminium and titanium.

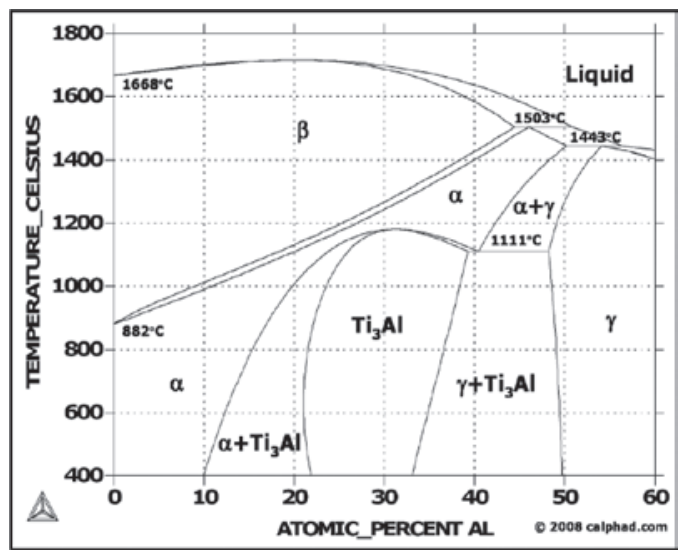

Fig. 2. Phase diagram of the Ti-Al

Complex aluminium and titanium nitride (AlTi) N, which is based on the crystal lattice of aluminium nitride, has good heat-resistance at temperatures around $800{ }^{\circ} \mathrm{C}$. When oxidising, the sustainability of the aluminium oxide, $\mathrm{Al} 2 \mathrm{O} 3$, on the surface is formed. The conglomerate structure is a highly nanostructured composite material comprising a matrix and reinforcement. A plastic inter- metallic matrix provides acceptable ductility and relaxation of internal stresses arising during thermocycling: heating to operating temperature and rapid cooling. The combination of two or more crystal lattices in the layer prevents the strong growth of each other.

The third nitride layer must consist of a composite nitride (AlTi)N with a crystal lattice based on aluminium nitride. The layer acts as an additional thick protective coating with a nanocrystalline structure and improves durability of the conglomerate and blades in general through the formation of aluminium oxide on the surface. The aluminium oxide is renewed when it is damaged and thus the protective properties of the coating are maintained at a sufficient level during operation. The thickness of nitrides due to the danger of strong spallation is limited to a few microns, and it is assumed that the main part of the coating will have a conglomerate or intermetallic structure.

\section{Analysis of the factors that determine the concept of the physical model of the heat-resistant nanocoating}

\section{The design features}

As a research object, the titanium alloy OT4-1 compressor stator blades of a helicopter engine (Fig. 3) are selected. The blades of the last stage compressor stator have particularly limited thickness; on several engine models maximum profile thickness is less than $1 \mathrm{~mm}$. Any change in the geometry of the blade profile through the coating results in a change in the flow regimes. Change in overall engine airflow and compression ratio also affects fuel consumption and the efficiency of the engine. The relative thickness of the profile is a percentage value, and a $1 \%$ change leads to producing a new profile with different aerodynamic characteristics. For these reasons, coating applied to the finished blade without special geometric calculations must be within $1 \%$ of the thickness of the blade. Thus, on a 1-mm-thick blade the amount of coating for both sides should be less than $10 \mu \mathrm{m}$, i.e. $5 \mu \mathrm{m}$ per side, in contrast to most coatings on turbine blades, where the thickness of the coating may be up of tens and sometimes hundreds of microns.

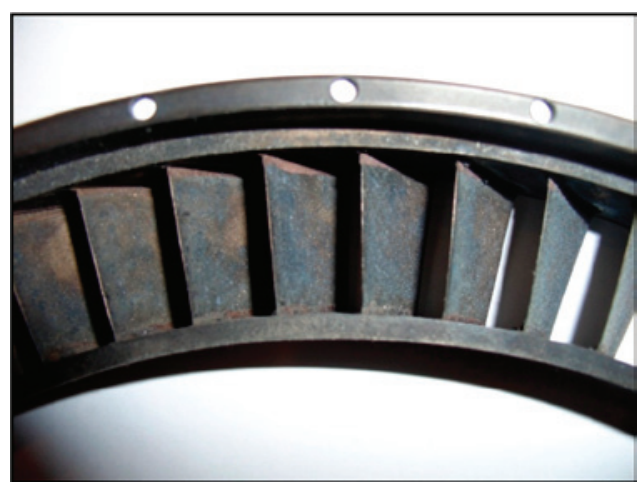

Fig. 3. The stator of the GTE compressor 


\section{Material science features}

The structure of the coating formed must contain a minimum amount of droplet phase formed during the ionplasma deposition arc sputter (Figs 4-5). Evaporation of any metal by a low-pressure arc is accompanied by the formation of large droplets of different sizes.

Some droplets having poor adhesion to the main coating may drop from its structure and form significant defects as pores (Fig. 4). As a result, there are localised areas of low heat resistance. The maximum aluminium and titanium droplet size is $0.1-100 \mu \mathrm{m}$ and $0.2-15 \mu \mathrm{m}$, respectively. The load of light aluminium ions in combination with low ionisation does not allow clean sputtering and increases the time or makes it virtually impossible to heat parts of ion bombardment without material depositing on the surface.

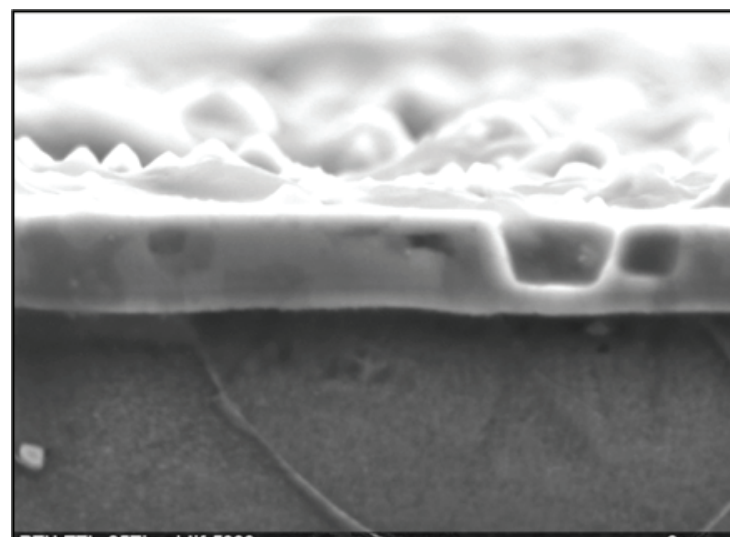

Fig. 4. Coating defects as a result of a large drop $(\times 5,000)$

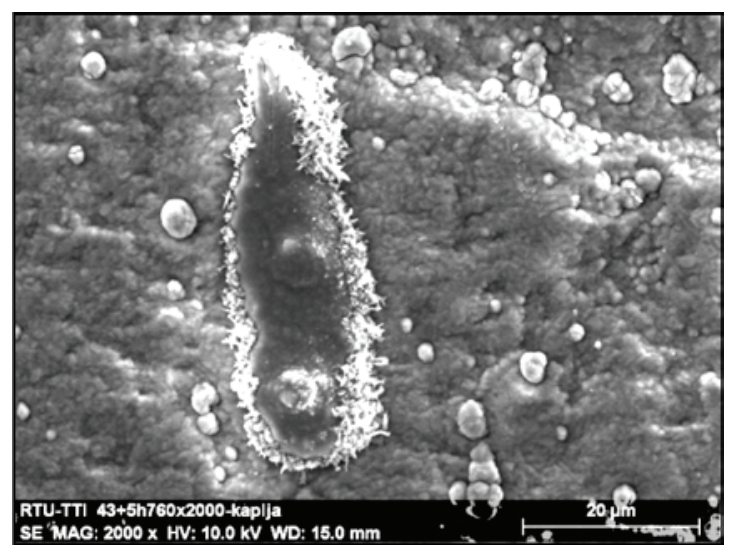

Fig. 5. Formation of needle-shaped titanium oxide on the limits of a large drop $(\times 2,500)$

\section{Technological features}

To eliminate the influence of the droplet phase on the quality of the coating formed, significant modification of the NNV-6,6-I1 ion-plasma coating equipment was done. The modernised equipment (Fig. 6) has three deposition material sources: two arc evaporators and a planar DC magnetron sputter (Urbahs et al. 2011a, b, 2012).
It was decided to vaporize titanium by arc spray and aluminium in a magnetron sputtering source.

The first arc evaporator, L1, is the source of the material being deposited, i.e. titanium, and a device for the primary ion bombardment. The arc source has a minimum current evaporator of $45 \mathrm{~A}$. A special central shield is placed before the arc evaporator to provide a predetermined ratio of titanium and aluminium and to reduce the droplet phase in the coating.

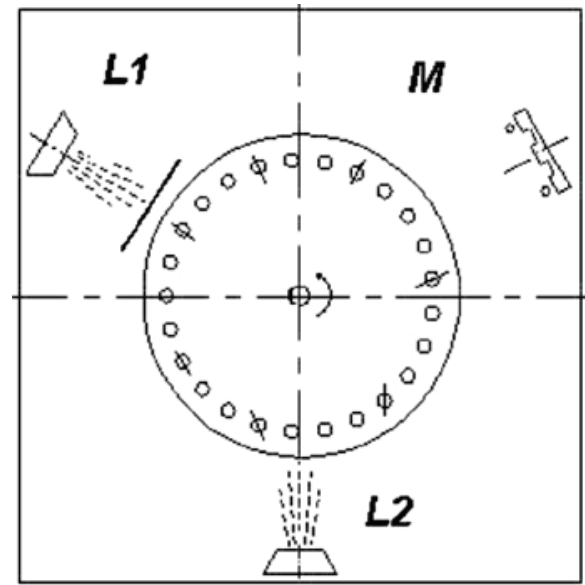

Fig. 6. The scheme of deposition

The second titanium arc evaporator, L2, is used without the aforementioned shield and only for heating and cleaning blades before deposition. A Magnetron-2 DC planar magnetron is M. Feed gas is carried out separately. Argon is supplied to the gap between the cathode and the anode, helps in the sputtering of aluminium, and regulates the base pressure in the chamber during ion cleaning, glow discharge, ion bombardment, and deposition. Nitrogen is separately supplied at two points of the chamber. Both gases flow through different inlet valves. Argon is supplied via the SNA-2 inlet valve and the flow of gas is manually regulated. Nitrogen is fed through the inlet valve solenoid with an automatic control.

\section{Technological realisation of the deposit of individual layers of nanostructured coatings}

\section{Intermetallic coating}

For the intermetallic coating, a specified chemical composition scheme is applied (Fig. 7).

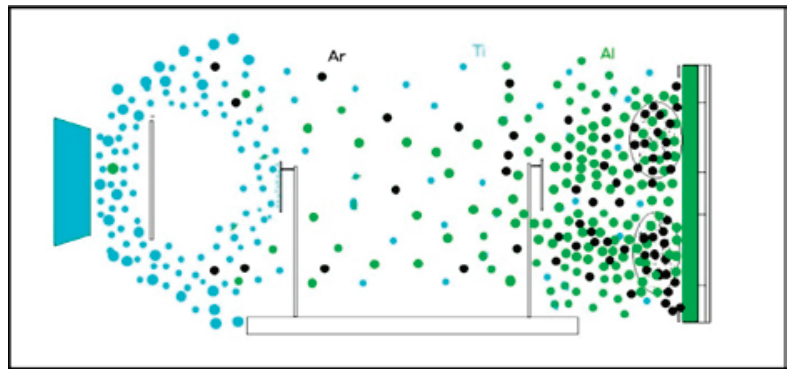

Fig. 7. Schematic diagram of intermetallic coating 
The evaporator current (50 A) supports the required amount of titanium on the surface of the blades. The stabilising coil current $(0.7 \mathrm{~A})$ provides stable and uniform titanium cathode evaporation. The focusing coil current $(0.5 \mathrm{~A})$ accelerates the flow of titanium plasma toward parts, increases its density at the central part of the evaporator, and sufficiently separates the dripping phase. The magnetron current (A) regulates the sputtering of aluminium. The voltage on the magnetron $(400 \mathrm{~V})$ is maintained automatically. Argon pressure of 6.10-4 mmHg provides adequate sputtering speed of the aluminium target.

Rotating the blades on the axis and rotating the table ensure alignment of the chemical composition of the layer. Due to this, the blades will constantly be in areas with different concentrations of elements and a thin film of coating of individual atoms of titanium and aluminium will be formed. The reference voltage on parts is $60 \mathrm{~V}$ and is the maximum possible to increase the density and temperature of deposited material without reducing the thickness of the coating.

\section{Conglomerate coating}

For a conglomerate coating, it is essential to ensure the simultaneous presence of nitrides and intermetallic compounds of titanium and aluminium. The sputtering scheme is therefore changed (Fig. 8). The main difference from the sputtering of the intermetallic compound is that nitrogen spraying into the chamber is added to the reaction. The gas is supplied from two sides of the chamber. When moving from the cathode to the surface of the blades, the vaporised material consisting of neutral atoms, ions and drops undergoes collisions with atoms and ions of gases.

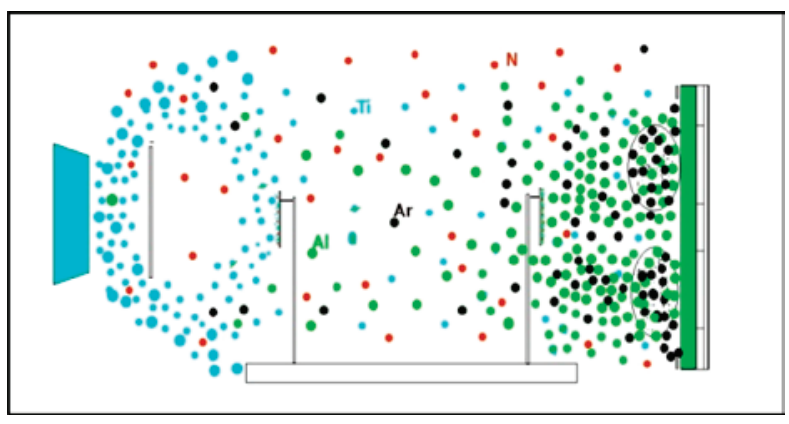

Fig. 8. Schematic diagram of obtaining conglomerate deposition

Argon is supplied to the magnetron on the magnetron target surface in an amount required to form a certain thickness of the buffer zone, which partially prevents the penetration of nitrogen. To facilitate the control of sputtering, the pressure of argon up to $3 \times 10$ $3 \mathrm{mmHg}$ is increased. The flow of nitrogen is controlled by an automatic system, and its partial pressure within the range of $0.4 \times 10-3 \mathrm{mmHg}$ is provided. The total pres- sure in the chamber is $3.4 \times 10-3 \mathrm{mmHg}$. Basic parameters for deposition are the following: titanium evaporator current - 50 A, stabilising coil current - 0.7 A, focusing coil current - 0.5 A, magnetron current - $7 \mathrm{~A}$, and the reference voltage on the parts $-80 \mathrm{~V}$.

The voltage on the magnetron $(280 \mathrm{~V})$ is reduced by the effect of 'poisoning' the cathode with nitrogen.

\section{Nitride coating}

To obtain the nitride coating (Fig. 9), it is necessary for a sufficient part of the metallic plasma to react with the nitrogen to form a nitride. This can be achieved by increasing the partial pressure of the nitrogen to $1.4 \times 10$ $3 \mathrm{mmHg}$ where the electron mean free path without collision with atoms of nitrogen is less than $3-5 \mathrm{~cm}$. Total pressure was maintained at $4.4 \times 10-3 \mathrm{mmHg}$.

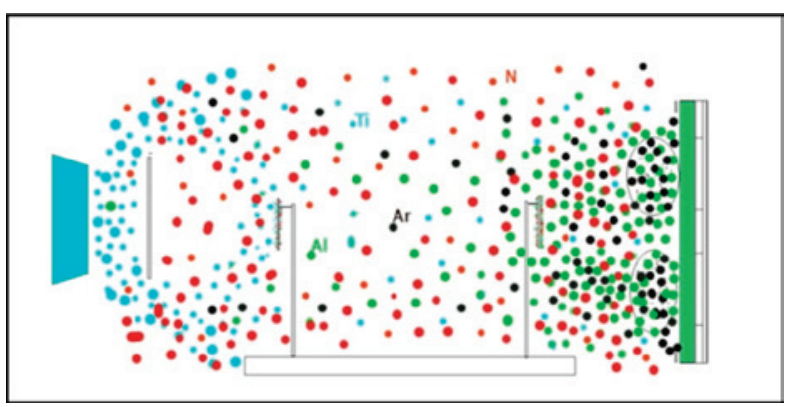

Fig. 9. Schematic diagram of the preparation of the nitride coating

Basic parameters for deposition are the following: titanium evaporator current - $50 \mathrm{~A}$, stabilizing coil current - 0.7 A, focusing coil current - $0.5 \mathrm{~A}$, magnetron current $-7 \mathrm{~A}$, and the reference voltage on the parts $-80 \mathrm{~V}$.

The voltage on the magnetron $(220 \mathrm{~V})$ is reduced by the effect of 'poisoning' the cathode with nitrogen.

\section{Investigation of service properties of coating}

For the case of sputtering of a multi-component coating by arc evaporation with ion bombardment, two aluminium evaporators and one titanic evaporator were used. The first sub-layer was sputtered in a composition adjustable argon environment, the second one in the mixture of argon and nitrogen (2N-Ar), and the third one in a rarefied atmosphere of pure nitrogen. As a result, three-layer nanostructured coatings, the internal sub-layer of which consists of intermetals $\mathrm{Al}_{\mathrm{x}} \mathrm{Ti}_{\mathrm{y}}$ with fine-grained conglomerate-type structure, were obtained. Its main purpose is to provide a diffusion bond with the basic material of a part. The centre conglomerate barrier layer has high hardness and sufficient viscosity. The outer ceramic layer with high recrystallization temperature has good anti-oxidation properties.

The multilayer coatings obtained had a smooth surface with a blue blade pressure side and a grey-blue back. The general thickness of the coating was about $20-40 \mu \mathrm{m}$. 
During the investigation of the characteristics of the coatings obtained, several tasks were carried out:

- evaluation of thermal stresses;

- measurement and analysis of microhardness distribution in the coating section;

- heat resistance tests;

- analysis of coating microstructure.

The evaluation of thermal stresses was performed visually on the basis of the value of deformation of thin samples (with thickness up to 1-2 $\mathrm{mm}$ ) and on the basis of breaking off and flaking off of coatings from thick samples. It should be noted that, in particular, on the basis of these conditions, i.e. the absence of deformation and flaking after sputtering and after heating, the selection of sputtering modes was carried out.

Microhardness $(\mathrm{H} \mu, \mathrm{MPa})$ in the section of the multiphase coating was measured by means of a PMT-3 device according to the standard methodology, which is a variety of Vickers hardness test (HV) and differs from it only by the use of smaller loads and, correspondingly, by the smaller size of indentation.

Correct tetrahedral diamond pyramid with an apex angle of $136^{\circ}$ was used as the indenter, which was gently pressed into the sample under load $0.05-5 \mathrm{~N}$. Microhardness of the outer layer of the coating was evaluated from the surface and exceeded 10,000 $\mathrm{MPa}$, which provided the coating good erosion resistance.

Comparative testing of the heat resistance of the different experimental samples was made. During the combined deposition, three options of Ti-Al-N compositions were chosen as coatings for the samples (Fig. 10): 75-intermetallic, 76-conglomerate, and 77-nitride. Coating thickness in all cases was less than 1-2 microns. A titanium ti-et sample without coating was used as a standard for comparison.

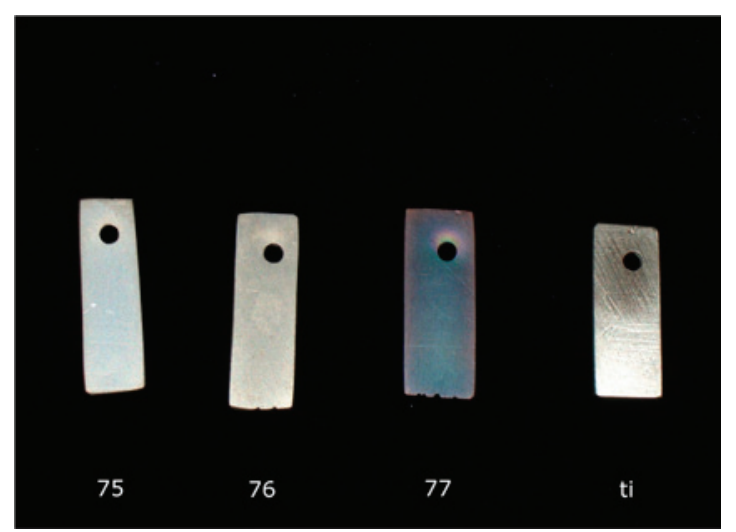

Fig. 10. Samples before heat resistance tests

The heat resistance tests were conducted in a furnace. When the furnace was heated to the desired temperature, the samples were loaded in the furnace for 1 hour and afterwards cooled in the air.
Test temperatures were $500^{\circ}, 550^{\circ}, 600^{\circ}, 650^{\circ}, 700^{\circ}$, $725^{\circ}, 750^{\circ}, 775^{\circ}, 800^{\circ}$ and $825^{\circ} \mathrm{C}$. The protective properties of the coating were evaluated by the graphs of a sample gain in weight, the values of the true gain in weight at certain temperatures, and efficiency ratio $\mathrm{Kt}^{\circ}$, defined as the ratio of the reference sample to the coated sample gain in weight at the test temperature.

After each stage of the test, the samples were photographed and weighed and the colour and condition of the surface were analysed. Figure 11 shows the test results obtained by sample oxidation.

Additionally, for the results of tests under certain temperatures when changes in the surface of the samples were visually observed, a study was made of the microstructure and chemical composition of the coating with a Hitachi-S3000N scanning electron microscope and a BRUKER X-ray energy dispersive spectrometer.

Studies of the microstructure of coatings (Fig. 12) with scanning electron microscopy were used to identify the main features of the process of coating damage during high temperature oxidation.

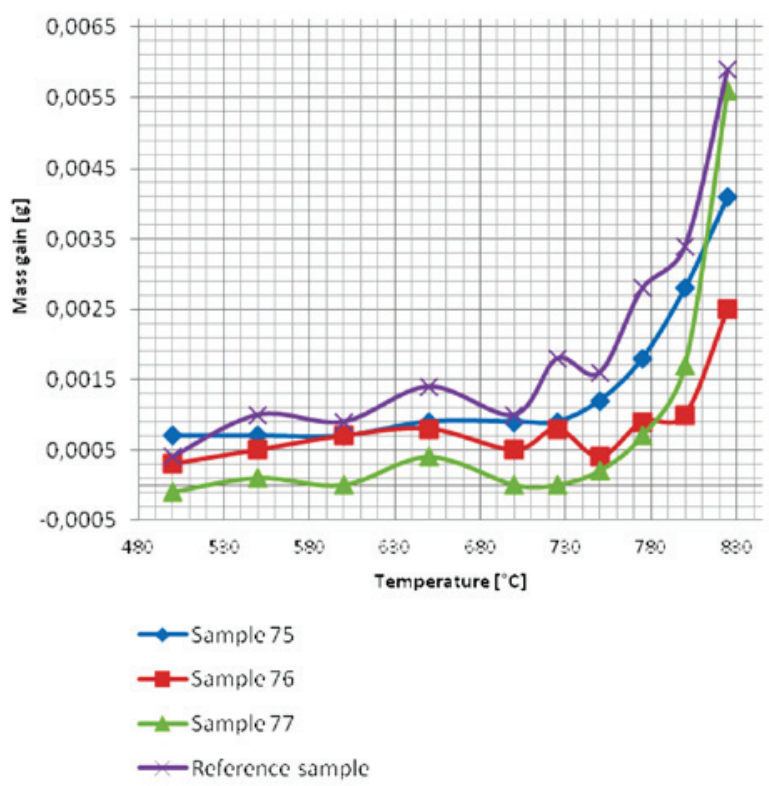

Fig. 11. Gain in mass depending on temperature (Urbahs et al. 2011a)

As a result of the tests, the following features of the oxidation process for the different samples were revealed (Fig. 11).

For the reference sample (without coating), gradual oxidation until $700{ }^{\circ} \mathrm{C}$ is detected. The microstructure of the surface does not undergo significant changes. Further increase in temperature leads to a sharp increase in the rate of oxidation, and the surface becomes matte (which is characteristic for yellowish titanium oxides). The original topography is smoothed out and the chart of oxidation at about $800^{\circ} \mathrm{C}$ shows a sharp turnaround. 


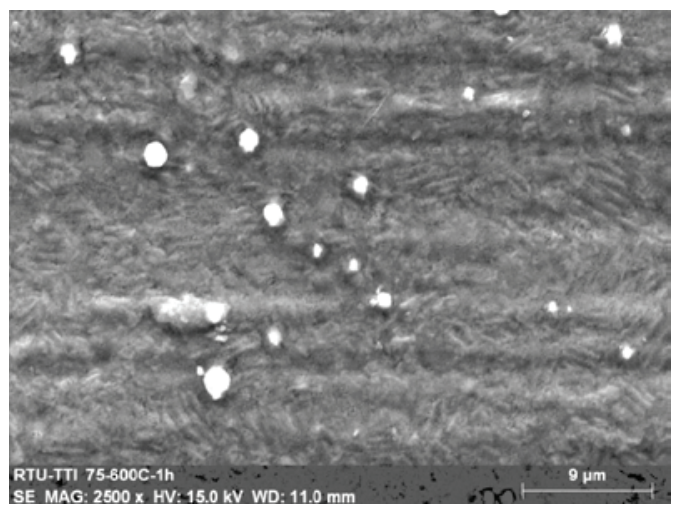

a. $600{ }^{\circ} \mathrm{C}$

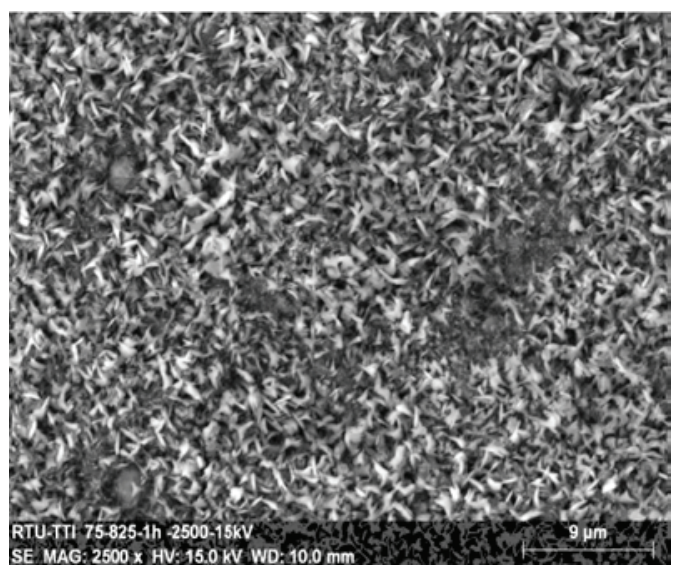

b. $825^{\circ} \mathrm{C}$

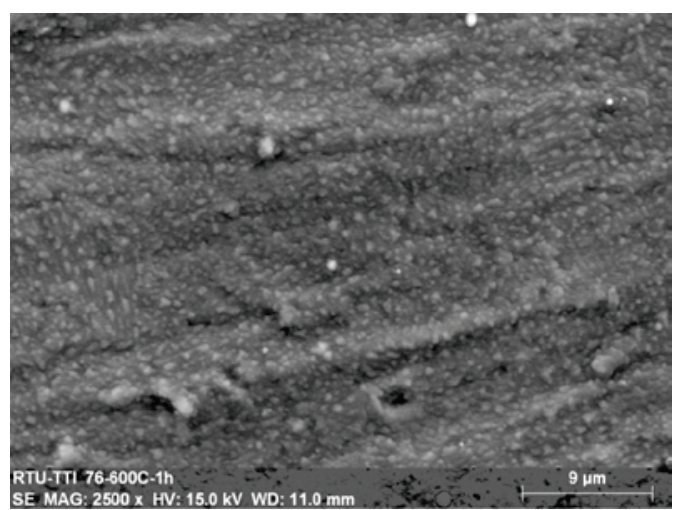

c. $775^{\circ} \mathrm{C}$

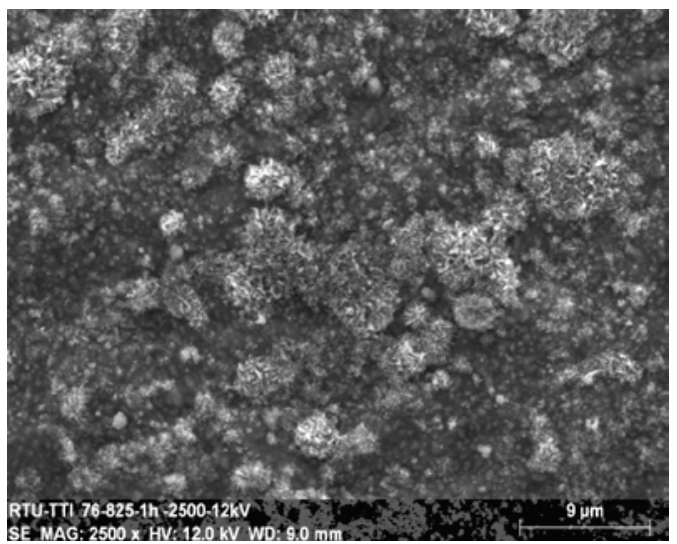

d. $825^{\circ} \mathrm{C}$

Fig. 12. Changes in topography of samples 75 (a, b) and 76 (c, d) during heat resistance tests
At a temperature of $825{ }^{\circ} \mathrm{C}$, the strongly oxidized layer becomes hilly and begins to crumble (Fig. 13).

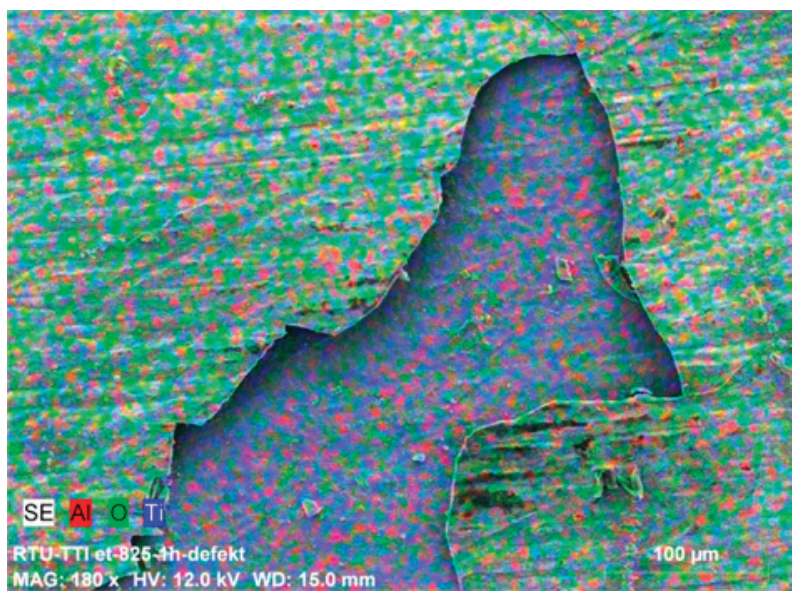

Fig. 13. Delamination of oxide layer on a reference sample (without coating)

The ratio of $\mathrm{Al} \%$ / Ti\% during the tests varies from 0.04 to 0.07 . This may indicate the formation on the surface of the reference sample of a thin film of aluminium oxide that is part of the reference sample and the removal of the titanium part in the form of its oxide.

For the sample with intermetallic coating (sample No. 75), significant oxidation is not observed until $650 \mathrm{C}$, and the colour and texture of the coating is maintained in the form of elongated micrograins.

Starting at a temperature of $750 \mathrm{C}$, the oxidation rate increases gradually and areas of needle-like oxide are formed on the surface, which, when the temperature reaches $825^{\circ} \mathrm{C}$ cover almost the entire surface of the sample (Fig. 2). The efficiency ratio of the coating is 1.33 at $750{ }^{\circ} \mathrm{C}$.

The conglomerate coating (sample No. 76) has stable heat-resistant properties in a wide range of temperatures. In particular, until a temperature of $800{ }^{\circ} \mathrm{C}$, gain in weight of oxides is low, the microstructure of the conglomerate surface has a grain size of about $400 \mathrm{~nm}$, and small colour changes are constant.

At a temperature of $825{ }^{\circ} \mathrm{C}$ there are some areas of growth of micro-needle-type oxide. The coating becomes matte and grey-blue in colour. The efficiency ratio of coatings at $750^{\circ} \mathrm{C}$ is 4.0 .

For the nitride coating (sample No. 77), the lowest rate of oxidation at temperatures up to $725^{\circ} \mathrm{C}$ is shown.

The initial coarse-grained structure, typical for titanium alloy after ion sputtering, becomes a bit unclear due to the formation of a thin oxide layer, and a fairly wide range of colour change is shown.

At a temperature of $775^{\circ} \mathrm{C}$, a micro-needle-type grid forms at the boundaries of the base grains, and it gradually covers the entire surface with an increase in temperature up to $825{ }^{\circ} \mathrm{C}$. The efficiency ratio of the coating at $7500^{\circ} \mathrm{C}$ is 8.0 . 


\section{Conclusions}

The main results of the research are as follows. Sputtering technology using the ion-plasma method was developed to create multicomponent nanostructured multilayer aluminium-titanium coatings for high-pressure compressor blades for gas turbine engines.

The internal intermetallic layer of the coating provides a diffusion bond with the base parts of the material. A centre conglomerate layer is characterised by high hardness and adequate viscosity and also has adequate damping and barrier properties.

The outer ceramic layer with high recrystallization temperature has good anti-oxidation properties and low-resolution ability under high operating temperatures. The heat resistance tests showed that the first signs of the destruction of the coated sample surface increases 2-3 times in comparison with the samples without coating. These tests have proven that the coatings developed can operate at temperatures up to $600-750^{\circ} \mathrm{C}$.

\section{Acknowledgements}

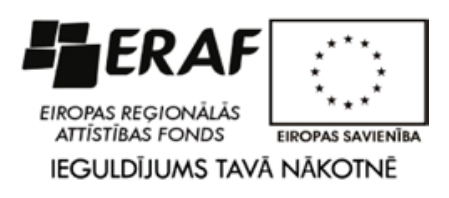

This work has been supported by the European Regional Development Fund within the project Development of Industrial Technology Prototype for Multi-component Nanostructured Ion-plasma Wear-resistant Coatings, No. 2010/0299/2DP/ 2.1.1.1.0/10/APIA/ VIAA/135.

\section{References}

Anikin, V.; Blinkov, I.; Volkhonskii, A., et al. 2009. Ion-plasma Ti-Al-N coatings on a cutting hard-alloy tool operating under conditions of constant and alternating-sign loads, Russian Journal of Non-Ferrous Metals 50(4): 424-431. http://dx.doi.org/10.3103/S1067821209040233

Dorfman, M.; Nonni, M.; Mallon J., et al. 2004. Thermal spray technology growth in gas turbine coatings. Thermal Spray. Advances in Technology and Applications, in Proceedings of the International Thermal Spray Conference, Osaka, Japan, 2004, 90-94.

Gunston, B. 1990. World Encyclopedia of Aero Engines: From the Pioneers to the Present Day. Sutton Pub. Ltd.

Lahtin, Yu. M.; Leontieva, V. P. 1990. Properties of Materials. Maskva: Mashinostroenie.

Urbahs, A.; Savkovs, K.; Kurjanovičs, I., et al. 2011a. Heat resistant coating for titan alloy-based parts of a gas turbine engine, in Proceedings of 15th International Conference Transport Means, 225-228. ISSN 1822-296x.

Urbahs, A.; Savkovs, K.; Urbaha, M. 2011b. High temperature oxide resistant components of perspective high strength intermetalceramic composite coatings, AES Technical Reviews International Journal 1(1): 53-57. ISSN 1916-5374.

Urbahs, A.; Savkovs, K.; Urbaha, M., et al. 2012. Nanostructured intermetal-ceramic coatings for blades of gas turbine engines, in NATO SCIENCE FOR PEACE AND SECURITY SERIES. Series B: Physics and Biophysics, Nanodevices and Nanomaterials for Ecological Security Part 2: 307-314. 